\title{
TRANSFORMACIONES EN LAS INSTITUCIONES DE GOBIERNO LOCAL DE LAS CIUDADES CASTELLANAS DURANTE LA REVUELTA COMUNERA (1520-1521)
}

\author{
por \\ MÁximo Diago HERNANDo
}

Instituto de Historia. CSIC. Madrid

RESUMEN: . Se analizan en este trabajo los cambios que tuvieron lugar en la composición de los órganos de gobierno de las principales ciudades de. Castilla en los años 1520 y 1521 , durante la revuelta comunera. Se interpretan estos cambios como una consecuencia de la presión ejercida desde los sectores dirigentes del Común de pecheros para poder participar en el ejercicio del poder local junto con los miembros de la oligarquia noble. También se pone de manifiesto que esta presión ya la babian empezado a ejercer con creciente intensidad durante las dos primeras décadas del siglo XVI, cuando proliferaron los enfrentamientos entre los regidores y los nuevos líderes de los pecheros.

Palabras Clave: Instituciones de gobierno urbano. Castilla. Siglo XVI. Revuelta comunera. Conflictos políticos

ABSTRACT: The author analyses in this article the changes that took place in the composition of the town councils of the main Castilian towns during the years 1520 and 1521, when the revolt of the Comunidades took place. These changes are explained as a consequence of the pressure that the leading sector of the Commoners exercised in order to be allowed to share local power with the members of the noble oligarchy. The author also proves that they had begun to exercise this pressure with increasing intensity during the first two decades of the sixteenth century, when conflicts proliferated in many Castilian towns between the aldermen (regidores) and the new leaders of the Commoners.

KEY WORDS: Municipal institutions. Castile. Sixteenth Century. The Revolt of the Comunidades. Political Conflicts. 
El movimiento de las Comunidades de Castilla se desarrolló en dos grandes frentes, ya que los rebeldes no se marcaron como único objetivo tomar bajo su control las instituciones de gobierno central del reino, para acometer una reforma radical de las mismas, sino que por otro lado también aspiraron a ordenar conforme a nuevos criterios el reparto social del poder en los ámbitos locales, procediendo para ello a una intensa reforma de las instituciones de gobierno concejil. En este sentido no estamos plenamente de acuerdo con la tesis en su momento propuesta por Juan Ignacio Gutiérrez Nieto, cuando afirmó que no se puede hablar de la existencia de un específico ordenamiento comunero para la organización municipal'. Pues por un lado es cierto que, si por ordenamiento entendemos un proyecto coherente definido con el objetivo de aplicarlo uniformemente a todos los municipios castellanos, nada semejante encontramos en los escasos textos programáticos a través de los cuales podemos reconstruir las líneas principales del proyecto político comunero. Pero, por otro lado, si descendemos al análisis de los cambios que efectivamente tuvieron lugar en el régimen de funcionamiento de los órganos de gobierno de las ciudades en los años 1520 y 1521, podremos comprobar que fue precisamente éste uno de los terrenos en que mayores transformaciones generó a corto plazo el desencadenamiento de la revuelta comunera.

Por ello, teniendo en cuenta que hasta ahora en los estudios sobre las Comunidades se ha dado prioridad al análisis de su faceta como movimiento dirigido contra las instituciones de gobierno central de la monarquía, y muy en particular contra el Consejo Real, consideramos necesario para profundizar en la comprensión de este complejo conflicto prestar también atención a su otra faceta como proceso orientado a transformar las relaciones de poder en los ámbitos locales ${ }^{2}$.

Si se parte de la idea de que la revuelta de las Comunidades fue un movimiento de rebelión de los "patriciados urbanos» contra una monarquía que había tendido de forma abusiva a hacer causa común con la alta nobleza, tal como ha propuesto Haliczer ${ }^{3}$, cuesta bastante admitir que uno de sus principales objetivos fuese el de reformar las instituciones de gobierno urbano, más allá

1 GutiÉRreZ NiETo, José Ignacio: «Semántica del término «comunidad» antes de 1520: las asociaciones juradas de defensa». Hispania, 136 (1977), p. 362.

2 A esta faceta presta también atención preferente la reciente monografía de Pablo SÁNCHEZ LEÓN: Absolutismo y comunidad. Los orígenes sociales de la guerra de los comuneros de Castilla, Siglo XXI, Madrid, 1998. Pero, aunque la obra se presenta como un análisis global del movimiento comunero; lo cierto es que sólo toma en consideración para definir su modelo interpretativo los casos concretos de dos ciudades, Guadalajara y Segovia, prestando escasa o nula atención al resto de las ciudades. Este desinterés por el resto de las ciudades queda reflejado en la bibliografía citada. Analizamos más en detalle el enfoque metodológico de esta obra y de otras que han analizado desde una perspectiva global el conflicto de las Comunidades en DiAgo HERnANDO, Máximo: Le comunidades de Castiglia (1520-1521). Una rivolta urbana contro la monarchia degli Asburgo, Edizioni Unicopli, Milano, 2001.

3 Haliczer, Stephen: The Comuneros of Castile. The Forging of a Revolution, 1475-1521, Madison, 1981.

Hispania, LXIII/2, núm. 214 (2003) 623-656 
por supuesto de la eliminación de los corregidores, por su condición de representantes del poder monárquico en las ciudades. Pero, si dejamos a un lado concepciones apriorísticas y nos centramos en el análisis de lo que sabemos que ocurrió en las distintas ciudades en particular en los años 1520 y 1521, que es bastante menos de lo que desearíamos saber para poder comprender mejor el sentido de los procesos que entonces tuvieron lugar, comprobaremos que, en efecto, en esos años se desencadenaron en muchas de ellas enconados conflictos internos entre los grupos oligárquicos y un amplio segmento de la población, en el que predominaban los pecheros, aunque también militaron a veces por motivos muy diversos miembros de familias de las oligarquías, y sobre todo del estamento privilegiado hidalgo, que lucharon por imponer un régimen de gobierno local que garantizase una más amplia participación del conjunto de la población en las instituciones.

El hecho de que hubo muchos regidores y otros reconocidos representantes de las oligarquías urbanas entre los comuneros más comprometidos no nos debe hacer olvidar que en aquellas ciudades en que triunfó el movimiento de las Comunidades se impusieron una serie de medidas de reforma del régimen de gobierno local que atentaron directamente contra los intereses del conjunto de los regidores, puesto que obligaron a estos oficiales a compartir el ejercicio del poder con representantes de otros sectores sociopolíticos que hasta entonces habían estado excluidos de las instituciones de gobierno local, o, si habían tenido acceso a las mismas, había sido con atribuciones muy restringidas.

Esta constatación plantea importantes interrogantes al estudioso de las Comunidades, pues, en principio, resulta falto de lógica que los regidores encabezasen un movimiento reivindicativo que apuntaba a socavar las bases sobre las que se fundamentaba el control del poder local ejercido precisamente por dichos oficiales. Es cierto, no obstante, que, en conjunto, el número de regidores que militaron en el bando comunero fue muy inferior al de los que se declararon fieles al rey, o al menos adoptaron una postura ambigua y evitaron comprometerse. Pero, a pesar de todo, en determinadas ciudades, como Segovia, Toledo o Salamanca, fueron relativamente numerosos los regidores que se sumaron abiertamente a la rebelión, y desempeñaron un papel dirigente entre los insurrectos, hasta el punto de que varios de ellos tuvieron que pagar con su vida su compromiso.

Para ofrecer una explicación a la actuación de éstos se podría recurrir a la hipótesis de que se trataba de «renegados», que por convicción personal estuvieron dispuestos a renunciar a los privilegios propios de su grupo para contribuir a la construcción de una sociedad más equilibrada y justa. Un examen más detenido de las biografías de estos regidores comuneros, como Juan Bravo, Juan Padilla o Pedro Lasso de la Vega, nos obliga, sin embargo, a desechar como poco verosímil esta explicación. Ya que, según todos los indicios, todos ellos manifestaron poseer una desarrollada conciencia de pertenencia a un grupo oligárquico, por derecho propio legitimado para ejercer en régimen de exclusividad el poder 
en el ámbito local, y actuaron con frecuencia movidos por la ambición personal. Y así, por ejemplo, resulta revelador constatar que Juan Bravo accedió al desempeño del oficio de regidor de Segovia porque así se estableció en las capitulaciones matrimoniales que firmó con su suegro, el judeoconverso Íñigo López Coronel, quien se comprometió a renunciar en él el referido oficio que entonces estaba ocupando, y también el de camarero del rey $y^{4}$. Pues, no parece que una persona que había impuesto como condición para casarse el que se le cediese un oficio de regidor fuese la más predispuesta a movilizarse, arriesgando su vida y hacienda, para imponer una reforma radical de los órganos de gobierno de las ciudades castellanas que contemplase la supresión de la institución del regimiento.

En efecto, entendemos que entre los objetivos perseguidos por los miembros de las oligarquías urbanas castellanas que tomaron parte activa en la revuelta comunera no figuraba el de modificar el régimen de reparto del poder en los ámbitos locales, que todo ellos, sin apenas excepción, deseaban preservar inalterado. Más bien actuaron movidos por el afán de recuperar la influencia perdida en el ámbito cortesano, y quizás también por el deseo de asegurar a las oligarquías de las ciudades con voto en Cortes un mayor grado de participación en la toma de decisiones en las instancias centrales de gobierno y administración del reino. Pero para conseguir estos objetivos tuvieron que poner en marcha un proceso de rebelión contra la autoridad monárquica establecida, que se tradujo en la convocatoria de una Junta extraordinaria de ciudades, que generó un clima de inestabilidad en el conjunto del reino, y en cada una de las ciudades en particular, que fue aprovechado por determinados sectores de las sociedades políticas urbanas para reclamar cambios radicales en el régimen de funcionamiento de las instituciones de gobierno concejil, y en el reparto social del poder en los ámbitos locales.

En una primera fase en todas las ciudades que se declararon en rebelión contra Carlos I los regidores consiguieron mantener bajo su control los órganos de gobierno local, aun a costa de hacer algunas pequeñas concesiones a los sectores que reclamaban mayor capacidad de participación en dichos órganos. Pero a partir del verano de 1520 la situación se fue poco a poco radicalizando de forma incontrolada, y como consecuencia algunas ciudades decidieron distanciarse del bando rebelde, en parte porque sus oligarquías no deseaban una ruptura radical con la monarquía, y en parte también porque temían los efectos desestabilizadores que el progreso de la rebelión podía tener en las propias sociedades políticas urbanas. Así ocurrió, por ejemplo, en Burgos, Soria, o Cuenca, mientras que por otro lado en las ciudades que continuaron en abierta rebelión los representantes de los grupos oligárquicos que hasta entonces la habían encabezado comenzaron a perder el control de la situación, y otros grupos sociopolíticos se hicieron con el control de los resortes del poder local, e impusieron una reforma radical de las instituciones de gobierno.

\footnotetext{
4 FernÁndeZ, Luis: Juan Bravo, Caja de Ahorros, Segovia, 1981, p. 64.
} 
Como consecuencia fue en las ciudades que adoptaron un compromiso más decidido con la rebelión en las que las reformas en el régimen de gobierno local se impusieron en su versión más radical, que suponía prácticamente la supresión de los regimientos vitalicios. Pero también en otras que adoptaron una postura más ambigua se introdujeron cambios significativos en el régimen de gobierno local durante los años 1520 y 1521 , que conllevaron una notoria ampliación de la base social representada en la asamblea concejil, aunque en ellas los regidores continuaron manteniendo el control de los principales resortes de ejercicio del poder.

En los años 1520 y 1521 proliferaron, por tanto, en Castilla los conflictos por el acceso al ejercicio del poder local en el seno de las sociedades políticas urbanas entre los diferentes sectores que las conformaban. Dichos conflictos manifestaron, no obstante, rasgos singulares en cada una de las distintas ciudades en particular, en función de cuál había sido hasta entonces la relación de fuerzas entre los distintos grupos, y de cómo se había venido regulando la participación de éstos en las instituciones de gobierno local. Pero los conflictos desatados en las principales ciudades de la meseta presentan un importante elemento en común, que es la presencia de un fuerte movimiento reivindicativo procedente del estamento pechero y canalizado por un sector dirigente al que convencionalmente calificamos como elite del Común.

Es cierto que en el estado actual de la investigación sabemos muy poco sobre cómo se desarrollaron estos conflictos internos en las ciudades castellanas en los años 1520 y 1521, y sería deseable que en el futuro se dedicasen análisis monográficos a las distintas ciudades en particular, combinando la utilización de las fuentes documentales locales con las de los archivos centrales de la monarquía, en particular el de Simancas y los de las Chancillerías de Valladolid y Granada, para profundizar en el conocimiento de esta faceta del movimiento comunero. Pero con los datos actualmente disponibles se puede al menos avanzar la formulación de algunas hipótesis sobre el carácter que tuvieron dichos conflictos, y sobre sus repercusiones en el funcionamiento de las instituciones de gobierno local de las ciudades castellanas en 1520 y 1521.

Para explicar mejor el fenómeno en su contexto es necesario, sin embargo, tener en cuenta que el estallido de conflictos políticos en el seno de las sociedades urbanas castellanas en el transcurso del año 1520 no representó un suceso imprevisto y falto de precedentes, sino que por el contrario durante las dos décadas previas se había desarrollado un proceso de radicalización de los enfrentamientos entre los distintos grupos sociopolíticos que conformaban las sociedades políticas urbanas, que no puede ser ignorado a la hora de proporcionar una explicación a lo que ocurrió tras el estallido de la revuelta comunera. Y entre estos enfrentamientos, uno de los que alcanzó mayor relevancia fue el que protagonizaron en varias importantes ciudades los sectores dirigentes del Común de pecheros de un lado, y los regidores hidalgos de otro. 


\section{EL PROCESO DE MOVILIZACIÓN POLÍTICA DEL COMÚN DE PECHEROS EN LAS CIUDADES CASTELLANAS A PRINCIPIOS DEL SIGLO XVI}

A principios del siglo XVI los miembros del estamento pechero no tenían reconocida idéntica capacidad de participación en los órganos de gobierno local en todas las ciudades castellanas, sino que desde este punto de vista los contrastes que se daban entre unas y otras eran considerables. De manera que por un lado en algunas ciudades, como Valladolid, ninguna persona perteneciente a dicho estamento podía acceder a las asambleas del ayuntamiento, en las que sólo participaban los oficiales de la justicia y los regidores, reclutados en el seno de los dos linajes de caballeros hidalgos. Mientras que por el contrario en otras ciudades los pecheros no sólo estaban representados en la asamblea concejil, sino que el número de oficiales procedentes de dicho estamento constituían mayoría en el seno de esta asamblea frente a los oficiales que representaban al estamento hidalgo, como ocurría, por ejemplo, en Calahorras.

Las ciudades en las que los pecheros tenían reconocida una importante capacidad de participación en los órganos de gobierno local eran, no obstante, sin excepción núcleos de segundo rango, en muchos casos de marcado carácter rural. Mientras que por el contrario en los grandes núcleos urbanos los principales oficios de gobierno local, y en concreto las regidurías, tendieron a quedar reservados de forma exclusiva a los hidalgos. Es cierto que en algunas de estas ciudades de primer rango, y en concreto en varias de las que tenían reconocido el derecho a enviar procuradores a Cortes, existió la figura institucional de los regidores de pecheros, que en principio hubiese cabido presumir que fuesen representantes de este estamento, reclutados además en su seno. Tal vez fuese así en el siglo XIV, pero pronto estos regidores de los pecheros dejaron de mostrar diferencias significativas en cuanto a su modo de reclutamiento respecto al resto de regidores, constando que pertenecieron, al igual que el resto de los regidores, al grupo privilegiado hidalgo ${ }^{6}$.

De modo que en las ciudades castellanas de mayor rango la única vía de la que a fines de la Edad Media disponían los pecheros para hacer oír su voz en las asambleas concejiles era a través del envío de algún representante o procurador, puesto que los regidores representaban entonces de forma exclusiva los intereses del estamento privilegiado hidalgo, y más en concreto del sector oligárquico que se había consolidado en el seno del mismo. Sin embargo, no en todas las ciudades se contemplaba la posibilidad de que uno o varios representantes del estamento pechero pudiesen acceder de forma regular a las asambleas concejiles, y ejercer en las mismas el derecho de voz y voto, en igualdad

\footnotetext{
5 Vid. Diago Hernando, Máximo: «El concejo de Calahorra durante el reinado de los Reyes Católicos: Aspectos de su organización institucional», Berceo, 144 (2003), en prensa.

6 Por ejemplo, en Guadalajara consta que el propio conde de Coruña llegó a ocupar un regimiento del estado de pecheros. Vid. SÁnCHEZ LEÓN, Pablo: op. cit. p. 150.
} 
de condiciones con el resto de oficiales. Ya hemos indicado cómo en Valladolid no estaba contemplada tal posibilidad, y, en otras ciudades en las que se les permitía enviar algún representante, las atribuciones de éste eran muy limitadas, como ocurría, por ejemplo, en Ávila, donde el procurador de la Comunidad que en 1502 dispusieron los Reyes Católicos que se designase todos los años sólo podría acceder a las reuniones del regimiento sin voz ni voto ${ }^{7}$.

Durante el siglo XV, no obstante, había tenido lugar en el conjunto del reino de Castilla un proceso de fuerte crecimiento económico que favoreció la consolidación en sus principales núcleos urbanos de un grupo cada vez más numeroso de pecheros enriquecidos, que poco a poco fue desarrollando una conciencia política propia, y mostró una creciente disconformidad con su radical exclusión de los órganos de gobierno local. Por lo cual, ya durante la segunda mitad de dicho siglo, comenzaron a desarrollarse en diversas ciudades movimientos reivindicativos en el seno del estamento pechero, que en algunos pocos casos consiguieron arrebatar ciertas parcelas de poder a los grupos oligárquicos nobles, aprovechando coyunturas favorables, como la que se dio en la segunda mitad del reinado de Enrique IV. En concreto sabemos por los trabajos de Pardos Martínez que en Burgos tuvo lugar entre los años 1465 y 1475 una singular experiencia de participación del Común de pecheros, a través de sus diputados, en los órganos de gobierno local junto con los oficiales del regimiento ${ }^{8}$. También en Valladolid Adeline Rucquoi detectó un intenso desarrollo de la actividad política de la comunidad a través de las cuadrillas entre los años 1464 y $1469^{9}$. Y, por fin, recientemente Jara Fuente ha puesto de manifiesto que en Cuenca en 1465 llegaron a participar por un breve espacio de tiempo en el gobierno de la ciudad oficiales de extracción popular, como los cuadrilleros, los diputados, el procurador síndico y el procurador de los pecheros, con las mismas atribuciones que los regidores ${ }^{10}$.

Estos episodios de participación de representantes pecheros en el ejercicio del poder local, que probablemente no fueron los únicos que tuvieron lugar durante el siglo $\mathrm{XV}$, se concentran significativamente en torno al año 1465 , que marcó el momento de máxima debilidad del poder monárquico, y por consecuencia también el de máximo peligro para las ciudades realengas, que se vieron directamente amenazadas por los proyectos expansionistas de los linajes de alta nobleza, que aspiraban a someterlas a su autoridad, e incorporarlas in-

7 Vid. Moreno NúÑEZ, José Ignacio: Ávila y su Tierra en la Baja Edad Media (Siglos XIIIXV), Junta de Castilla y León, Valladolid, 1992, p. 146

8 PARDOS MARTíneZ, Julio A.: "Constitución patricia y comunidad en Burgos a finales del siglo XV (Reflexiones en torno a un documento de 1475)», en La ciudad bispánica durante los siglos XIII al XVI, Universidad Complutense Madrid, 1985, t. I, pp. 545-580.

9 RuCQuOI, Adeline: «Valladolid, del Concejo a la Comunidad», La ciudad hispánica durante los siglos XIII al XVI, Madrid, 1985, t. I, pp. 745-772.

10 JARA FUENTE, José Antonio: «Sobre el concejo cerrado: Asamblearismo y participación política en las ciudades castellanas», Studia Historica. Historia Medieval, 17 (1999), p. 128. 
cluso a todos los efectos a sus señoríos. Por lo cual resulta comprensible que en estas circunstancias de excepcional peligro, cuando incluso algunos de los miembros de los grupos oligárquicos eran considerados sospechosos de actuar en connivencia con los nobles enemigos de las ciudades, resultase más fácil arrancar concesiones al grupo gobernante, que no podía permitirse que a la amenaza exterior se sumase otra interior procedente de los propios grupos populares, que podía resultar sumamente peligrosa si éstos llegaban a ser eficazmente dirigidos por uno o varios líderes carismáticos.

En cualquier caso estos episodios tuvieron un marcado carácter pasajero, y, una vez que se estabilizó la situación política del reino tras la victoria de los Reyes Católicos en la "guerra civil», volvieron a consolidarse las formas de gobierno oligárquico en todas las principales ciudades realengas de Castilla. A pesar de lo cual no tenemos constancia de que durante su reinado la exclusión de los pecheros de toda participación en las tareas de gobierno urbano diese lugar al estallido de serios conflictos con los grupos oligárquicos.

Es cierto que para evitar que surgiesen este tipo de conflictos los propios monarcas tomaron algunas medidas que debían contribuir a aliviar los efectos de dicha exclusión, entre las que hay que destacar la creación a partir de la década de 1490 en varias ciudades de la figura institucional de los procuradores o personeros del Común ${ }^{11}$. Pero tales medidas no resultaron suficientes para acallar el descontento entre la población pechera, y muy en particular entre los sectores más concienciados políticamente de la misma, máxime cuando consta que en bastantes casos los procuradores tenían reconocidas escasas atribuciones, y además no sólo no eran elegidos directamente por los pecheros, sino que incluso en algunas ocasiones desempeñaban el oficio hidalgos.

De ahí que, en el período de inestabilidad que se inició en Castilla tras la muerte de la reina Isabel en 1504, las tensiones internas en el seno de las sociedades políticas urbanas, que se habían ido acumulando durante los años de aparente tranquilidad que se habían vivido bajo el gobierno de ésta, estallasen, dando lugar al planteamiento de abiertos conflictos en numerosas ciudades. Y uno de los factores que, sin duda, más contribuyó al desencadenamiento de estos conflictos fue la radicalización de la postura política de los sectores dirigentes del estamento pechero, que cada vez con mayor insistencia reclamaron que se les reconociese una mayor capacidad de participación en la toma de decisiones en el ámbito político local.

Hemos podido seguir con bastante detalle este proceso en la ciudad de Soria, donde el individuo que encabezó el movimiento de oposición política del Común de pecheros al grupo de regidores que controlaban la institución concejil durante la segunda década del siglo XVI, un platero de origen judeoconverso llamado Bartolomé García, destacó también como uno de los principales

11 Vid. LADERo QueSADA, Miguel Ángel: «Monarquía y ciudades de realengo en Castilla. Siglos XII a XV», $A E M, 24$ (1994), pp. 771-2.

Hispania, LXIII/2, núm. 214 (2003) 623-656 
dirigentes comuneros en el verano de 1520 , hasta el punto de que hubo de pagar con su vida su compromiso, al ser ejecutado a fines de septiembre de ese año por orden de los regidores y oficiales de la justicia locales ${ }^{12}$.

Este individuo recibió ya en marzo de 1512 un poder extraordinario del Común de pecheros de Soria para poder asistir a las reuniones del regimiento en representación de dicho estamento, en sustitución probablemente del procurador del Común, que según la costumbre debía asumir el desempeño de tal función. ${ }^{13}$. Desconocemos en concreto el motivo por el que se tomó esta decisión, pero un hecho del que sí tenemos constancia es que aquel año el Común estuvo muy agitado en Soria, hasta el punto de que el día 25 de julio, festividad de Santiago Apóstol, el nuevo procurador que había sido elegido el 24 de junio se atrevió a hacer una serie de requerimientos al corregidor, cuando éste se encontraba presidiendo una corrida de toros en la plaza mayor de la ciudad, y al no obtener de éste la respuesta esperada comenzó a «apellidar la Comunidad» y a pedir a voces que se repicase la campana de la Comunidad, por lo que finalmente fue detenido y llevado a prisión ${ }^{14}$.

La radicalización de las posturas políticas del Común de pecheros de Soria en el año 1512, de la que dan fe tanto el nombramiento como procurador extraordinario del platero Bartolomé García como los desórdenes del día de Santiago, provocó una inmediata respuesta de los regidores, que al año siguiente se negaron a admitir en las reuniones de ayuntamiento al nuevo procurador elegido por el Común el día de San Juan de 1513, alegando que era una persona de poca autoridad y de «opinión y parcialidad». Pero, además, no contentos con esto, elevaron ante el Consejo Real una propuesta para que se modificase el procedimiento de elección del procurador del Común, de modo que en adelante no fuesen los pecheros quienes lo eligiesen sino los propios regidores ${ }^{15}$. La propuesta de reforma no prosperó, pero el mero hecho de su presentación proporciona una buena prueba de la preocupación con la que desde las filas de la oligarquía se veía la radicalización de las posturas políticas del Común de pecheros. Y, en efecto, la evolución de los acontecimientos en Soria en los años siguientes demostró que estos temores de la oligarquía estaban sobradamente justificados, ya que a partir de 1517, aprovechando sin duda la fase de inestabilidad que inauguró en el reino la muerte de Fernando el Católico en enero de 1516, desde el Común se intensificó la campaña de desafío político al grupo oligárquico, que fue orquestada por el platero Bartolomé García, quien desempeñó tres años seguidos el oficio de procurador del Común, entre junio de 1517 y junio de 1520.

12 Vid. Diago Hernando, Máximo: «Las ciudades castellanas contra Carlos I: Soria durante la revuelta de las Comunidades», Celtiberia, 94 (2000), pp. 125-184.

13. Sobre la organización institucional del Común de pecheros de Soria Vid. Diago HernanDO, Máximo: Estructuras de poder en Soria a fines de la Edad Media, Junta de Castilla y León, Valladolid, 1993, pp. 243 y ss.

14 AGS, RGS, VIII-1512. Comisión al bachiller Juan Rodríguez de Molina.

15 Vid. Diago Hernando, Máximo: Estructuras de poder..., pp. 259-261. 
En concreto en febrero de 1517 Bartolomé García, cuando todavía no era procurador, ya consiguió movilizar a la institución del Común para que se presentase una petición al regente, el cardenal Cisneros, solicitando que no se prorrogase el corregimiento a Juan Velázquez de Cuéllar, como habían pedido los regidores. Él mismo acudió en persona a la Corte para tramitar esta solicitud, y probablemente fue el redactor del memorial dirigido al regente en que se denunciaba que durante los muchos años en que Juan Velázquez de Cuéllar había sido corregidor de Soria no se había impartido justicia en la ciudad, puesto que siempre había favorecido los intereses de los regidores, por lo cual los miembros de la Comunidad habían vivido muy oprimidos, y como consecuencia se encontraban muy necesitados de ser favorecidos en justicia, para no continuar siendo vejados por los principales de la ciudad ${ }^{16}$.

Las gestiones entonces llevadas a cabo por el combativo platero dieron su fruto, pues finalmente el cardenal Cisneros decidió no prorrogar el oficio de corregidor a Juan Velázquez de Cuéllar, y poco después nombró a un hombre de su confianza, Hernán Arias Dávila, quien nada más llegar a Soria despertó una hostil animadversión entre los regidores más influyentes, y en particular en Juan Morales, que había estado muy estrechamente vinculado con Juan Velázquez de Cuéllar, pues había sido varias veces corregidor de la villa de Arévalo, donde este último controlaba la tenencia de la fortaleza. El Común de pecheros por el contrario se alineó en esta ocasión con el nuevo corregidor, y por este motivo, sin duda, se enturbiaron aún más las relaciones entre el procurador Bartolomé García y los regidores, que alcanzaron en algunos momentos altas cotas de tensión, como cuando el regidor Juan de Barrionuevo llegó a llamarle públicamente «bellaco ladrón» y «revolvedor y alborotador de pueblo», tras haber tenido un incidente con él por haberle exigido que bajase el precio de los besugos ${ }^{17}$.

Además de en Soria, también en otras ciudades castellanas hemos podido comprobar que se dieron procesos de intensificación de la actividad política de los grupos dirigentes del Común de pecheros, que conllevaron una actitud de desafío a la autoridad de los grupos oligárquicos,. En concreto nos consta que en Ávila esta evolución generó preocupación en la oligarquía, que por ello intentó, como medida preventiva, poner bajo su control los órganos de representación pechera, y neutralizar así la figura institucional del procurador de pecheros.

En efecto, los Reyes Católicos habían dispuesto en 1502 , en respuesta a una petición de la Comunidad de pecheros abulense, que ésta designase cada año un procurador, que había de ser elegido el día de San Miguel por doce

16 Sobre la figura de Juan Velázquez de Cuéllar, que fue hombre de confianza de la reina Isabel al Católica, y su testamentario, vid. Diago Hernando, Máximo: «Los Velázquez de Cuéllar, tenentes de Arévalo, en el horizonte político castellano a fines de la Edad Media», Cuadernos Abulenses, 16 (1991), pp. 11-40.

17 AGS, RGS, XII-1519. Vid. también Diago HeRnando, Máximo: Estructuras de poder... pp. 257 y ss.

Hispania, LXIII/2, núm. 214 (2003) 623-656 
electores a razón de dos por cuadrilla. Según se informó a los reyes en los memoriales enviados para fundamentar la petición, hasta entonces ninguno de los dos estamentos en que se dividía la población laica, el de pecheros y el de caballeros y escuderos, había estimado necesario nombrar un procurador, debido a que hasta fechas muy recientes se había acostumbrado en la ciudad admitir en las sesiones concejiles a todas las personas que habían querido entrar. Y si había habido procuradores de los pecheros en los últimos años había sido sólo aquéllos que la justicia y regidores habían querido designar, los cuales no habían mantenido ninguna vinculación con el Común, salvo cuando tenían que proceder a recaudar impuestos entre la población pechera ${ }^{18}$.

Los regidores abulenses, que en 1502 habrían sufrido por lo tanto una importante derrota frente al Común, no se resignaron, sin embargo, a perder toda capacidad de control sobre la actividad política desarrollada por esta institución de representación de la población pechera. Y. en concreto así nos lo demuestra el hecho de que a comienzos de 1513 , el mismo año precisamente en que en Soria los regidores se negaron a recibir en el ayuntamiento al procurador del Común, e intentaron modificar el procedimiento de elección de este oficial, se denunció por representantes del Común de Ávila ante el Consejo Real que el oficial de la justicia, licenciado Valle, se había reunido en la iglesia de San Vicente con algunos caballeros e hidalgos abulenses, y habían designado como procurador del Común a un caballero hidalgo, para que entrase a las reuniones del regimiento en representación de los pecheros.

El Consejo Real atendió la denuncia de los pecheros, y poco después el Común abulense pudo elegir como su procurador a Gil Suárez Zimbrón, quien permaneció en el desempeño del oficio al menos tres años, puesto que en el otoño de 1515, cuando debería haber cesado en aplicación de la normativa vigente, se obtuvo autorización del Consejo Real para que se le concediese una prórroga, con el argumento de que estaba muy al corriente de ciertos negocios

18 Vid. Diago Hernando, Máximo: «Conflictos políticos en Avila en las décadas precomuneras», Cuadernos Abulenses, 19 (1993), p. 83 . En 1479 los Reyes Católicos habían dispuesto que a las sesiones de ayuntamiento de concejo asistiesen además de los regidores un procurador de la ciudad y dos de la Tierra «y hombres buenos pecheros de ella», los cuales no tendrían derecho de voto, a diferencia de los regidores. Se deduce, por tanto, que todavía no se contemplaba la existencia de la figura de un procurador del Común de la ciudad, ya que sólo se habla de procurador de la ciudad. Vid. LuIS LÓPEZ, Carmelo.: Documentación Medieval Abulense en el Registro General del Sello, vol. II, Ávila, 1993, doc. $\mathrm{n}^{\circ}$. 4. Otro documento del año 1495 hace constar, no obstante, que el Común de pecheros de Ávila había tenido por procurador a Rodrigo de Santa María, vecino de la ciudad, «que procurava e entendía en las cosas tocantes al dicho común, el qual diz que fue muerto en la dicha çibdad de Ávila por çiertos vezinos de ella». Por lo cual entonces los monarcas, atendiendo una petición del propio Común, ordenaron a su corregidor en Ávila que permitiese a los miembros de este estamento que entre ellos mismos pudiesen elegir y nombrar otro procurador, en sustitución del difunto. Vid. Casado Quintanilla, Blas: Documentación Real del Archivo del Concejo Abulense (1475-1499), Ávila, 1994, Doc. $n^{\circ}$. 110. No aclara, sin embargo, este documento si dicho procurador tenía derecho a asistir a las asambleas concejiles.

Hispania, LXIII/2, núm. 214 (2003) 623-656 
que se habían comenzado en la ciudad ${ }^{19}$. Y de hecho diversos indicios nos confirman que en esos años desarrolló una intensa actividad política, que fue valorada positivamente por la población pechera, y pudo granjearle algunas enemistades entre los miembros del grupo oligárquico: Puesto que, por ejemplo, en una ocasión defendió que se arrendasen unos términos baldíos que colindaban con lugares de señoríos, para atender las necesidades financieras del concejo, y evitar que se aprovechasen de dichos términos los vecinos de estos lugares, como entonces estaba sucediendo. Y esta medida es poco probable que resultase del agrado de más de un regidor abulense, como Pedro de Ávila, señor de Villafranca y Las Navas, quien con anterioridad ya había sido denunciado por tener ocupados algunos de los términos baldíos que Suárez Zimbrón proponía que se arrendasen ${ }^{20}$.

Por otro lado interesa destacar que en el programa que este procurador intentó llevar a la práctica durante su mandato se concedió prioridad al fortalecimiento de la capacidad de actuación política de la Comunidad. Y así lo demuestra la propuesta por él presentada ante el Consejo Real en 1514 para que en adelante se asignase un salario a los doce representantes que cada año elegían las seis cuadrillas de la ciudad, a razón de dos cada una, para «entender en todas las cosas cumplideras a la comunidad», argumentando que el desempeño de esta tarea política les privaba de bastante tiempo, que no podían dedicar a sus «labores y haciendas».

Los paralelismos entre la figura de Gil Suárez Zimbrón en Ávila, y la del platero Bartolomé García en Soria, son notables, aunque también entre ellos existen importantes diferencias, puesto que el abulense era hidalgo, miembro del linaje de San Juan, y además formaba parte de la clientela del duque del Infantado ${ }^{21}$. Y por ello cabe sospechar que se sirviese del aparato institucional del Común de pecheros como plataforma para la persecución de sus objetivos políticos personales ${ }^{22}$. En cualquier caso es todavía poco lo que sabemos sobre el desenvolvimiento de la vida política en Ávila en las dos primeras décadas del siglo XVI, y, sólo si se acometen nuevos estudios monográficos, se podrá avanzar en la caracterización de los principales protagonistas de la escena política local en este convulso período previo al estallido de la revuelta comunera, y determinar sobre bases más seguras las motivaciones de sus actuaciones. Por el momento simplemente podemos adelantar que en el año 1518 hemos consta-

19 Vid. Diago Hernando, Máximo: “Conflictos políticos en Avila...» pp. 84-5.

20 Íbid. p. 86.

21 Íbid. p. 99, doc. $\mathrm{n}^{\circ} .2$.

22 En varias ciudades castellanas del momento se constatan casos parecidos de hidalgos que incluso renuncian a sus privilegios estamentales para realizar carrera política como representantes de la población pechera. Es el caso de Pedro de Tordesillas, vecino de Chinchilla. Vid. Pretel Marín, Aurelio: La "Comunidad y República" de Chinchilla (1488-1520). Evolución de un modelo de organización de la oposición popular al poder patricio, Albacete, 1989, pp. 89 y ss. También el de Fernando de Maluenda, vecino de Soria. Vid. Diago Hernando, Máximo: Estructuras de poder...pp. 244-6. 
tado una notable ofensiva política del Común contra los regidores, que se tradujo en la presentación de varias denuncias de cierto calado ante el Consejo Real por su procurador Andrés Díaz ${ }^{23}$.

Junto con Soria y Ávila, una tercera ciudad en la que durante las primeras décadas del siglo XVI se intensificó la actividad política del Común de pecheros es Segovia, donde esta institución ya alcanzó una importante victoria en 1497 , cuando los reyes autorizaron a que sus diputados y procuradores pudiesen reunirse sin necesidad de que estuviesen presentes los regidores ${ }^{24}$. A partir de entonces el Común de pecheros segoviano desplegó una intensa actividad política que pronto provocó los recelos de la oligarquía de regidores, quienes, al igual que hicieron sus homólogos de Soria y Avila, también reaccionaron a la defensiva ante este desafío. $Y$ así lo demuestran los sucesos ocurridos el año 1511 , cuando se produjo un alboroto protagonizado por los regidores y los procuradores de la Comunidad, al negarse los primeros a admitir a éstos en las asambleas del regimiento ${ }^{25}$.

María Asenjo ha puesto en relación esta intensificación de la actividad política de la Comunidad segoviana con el fuerte progreso económico que experimentó la ciudad de Segovia desde mediados del siglo XV, y que fue propulsado precisamente por una incipiente burguesía artesano-mercantil integrada en la Comunidad de pecheros. Puesto que aquellos individuos que más activamente participaron en la vida política local desde la plataforma institucional del Común durante las primeras décadas del siglo XVI fueron dinámicos mercaderes y hombres de negocios, como Diego de Cuéllar ${ }^{26}$. Pero dado que esta autora detiene su análisis en torno al año 1516 queda todavía por clarificar cuál fue el papel que estos nuevos dirigentes pecheros desempeñaron en Segovia durante los años 1520 y 1521. Y así, por ejemplo, no sabemos con certeza si existió algún tipo de relación familiar entre Alonso de Cuéllar, quien representó a Segovia como procurador en la Junta de Tordesillas, y el Diego de Cuéllar que María Asenjo ha identificado como uno de los principales dirigentes del Común en las décadas previas al estallido de la revuelta.

En Guadalajara Sánchez León ha detectado también la emergencia a fines del siglo XV y principios del XVI de una "generación estable de líderes populares», puesto que cada vez resultó más frecuente que las personas que desempeñaban los oficios de "quatros" volviesen a ser reelegidos para el desempeño de este oficio, que permitía a la población pechera de esta ciudad contar con una amplia representación en la asamblea concejil ${ }^{27}$. Pero este grupo dirigente que se consolidó en Guadalajara en el seno del estamento pechero durante el reinado de los

23 Vid. Diago Hernando, Máximo: «Conflictos políticos en Ávila...», pp. 87-8.

24 Vid. Asenjo GonZÁLeZ, María: Segovia. La ciudad y su Tierra a fines del Medievo, Segovia, 1986, pp. 304-5.

25 Vid. ASENJO GONZÄLEZ, María: op. cit. p. 424.

26 Ibid. Pp. 303-8.

27 SÁNCHEZ LEÓN, Pablo: op. cit. p. 165. 
Reyes Católicos estuvo integrado en su mayor parte, según este autor, por artesanos, ya que los comerciantes optaron por participar en la vida política a través de otras vías, y en concreto mediante el desempeño de los oficios de jurados ${ }^{28}$. Y, por consiguiente, fueron artesanos los que en esta ciudad dirigieron el movimiento de oposición política a la oligarquía, por ejemplo a través de acciones orientadas a conseguir el envío de jueces de términos, que pusiesen fin a las ocupaciones de tierras que tenían efectuadas los caballeros y los campesinos ${ }^{29}$.

Sin embargo, en Guadalajara no se dio un clima de crispación en la relaciones entre Común y oligarquía de regidores semejante al que hemos constatado en otras ciudades, como Soria, Segovia o Ávila. Y ello en parte pudo deberse al hecho de que fueron artesanos los que allí lideraron al estamento pechero, y a que en la asamblea concejil de esta ciudad tenían entrada bastantes oficiales que representaban a dicho estamento. Pues, como consecuencia, los regidores no pudieron imponer allí un régimen de gobierno de fuerte signo oligárquico, máxime cuando entre ellos existían planteadas profundas diferencias entre aquéllos que formaban parte de la clientela política de los Mendoza, y los que mantenían una más estrecha vinculación con la monarquía. Y la propia presencia del duque del Infantado en la ciudad, controlando además los oficios de la justicia, sin duda contribuyó decisivamente a que no se desarrollase un potente movimiento de oposición a los regidores, encabezado por miembros del estamento pechero con fuerte concienciación política, ambición y deseo de participar en el ejercicio del poder, puesto que en última instancia él era el que mantenía el control de los resortes del poder en la ciudad, y con su presencia impedía que los regidores llegasen a conformar un grupo oligárquico propiamente dicho.

Una situación de signo completamente contrario a la de Guadalajara se vivía en las primeras décadas del siglo XVI en la ciudad de Valladolid, donde los regidores tenían asegurado un control exclusivo de los resortes del poder, por cuanto sólo ellos podían asistir a las sesiones de ayuntamiento junto con los oficiales de la justicia designados por el rey. Esta práctica debió generar un fuerte descontento entre los sectores dirigentes del Común de pecheros, pero de momento no conocemos muy bien en qué acciones se tradujo, a falta de estudios monográficos sobre la evolución de la vida política en Valladolid en las primeras décadas del siglo XVI. Sí tenemos constancia, no obstante, de que finalmente el descontento alimentó un poderoso movimiento reivindicativo, al que se adhirieron además de los pecheros los miembros del estamento eclesiástico y los universitarios, que consiguió en 1517 que el cardenal Cisneros acce-

28 Existen algunas pruebas adicionales que sugieren que había falta de sintonía entre el Común de pecheros de Guadalajara, dominado por artesanos, y los mercaderes. Así en 1517 el Común denunció al mercader Antonio Meléndez por haber procurado mediante presiones, con el apoyo de sus parientes y amigos, que la ciudad no aceptase el encabezamiento de las alcabalas, en contra de lo que deseaba la mayoría de la población. AGS, RGS, I 1517. Provisión dirigida a los alcaldes ordinarios de Guadalajara.

29 SÁnCHEZ LeÓn, Pablo. op. cit. pp. 154-6.

Hispania, LXIII/2, núm. 214 (2003) 623-656 
diese a introducir una importante reforma en el régimen de gobierno local, autorizando a que en adelante las catorce cuadrillas en que se agrupaba la población pechera vallisoletana designasen cada año dos procuradores que pudiesen entrar a las reuniones del regimiento en representación del estamento pechero, según se hacía en la ciudad de Burgos ${ }^{30}$. Y a pesar de que se trató de una concesión de alcance muy limitado, pues hemos de presumir que los procuradores que se autorizaba a designar sólo tendrían funciones consultivas y no capacidad decisoria, como ocurría en Burgos ${ }^{31}$, la reacción de los regidores fue de visceral oposición a la medida, amparándose en el argumento de que se habían de respetar los privilegios concedidos a la ciudad por Alfonso XI, en los cuales quedaba terminantemente prohibido que los pecheros pudiesen estar representados en el ayuntamiento.

Además de en las ciudades de primer rango, que tenían reconocido derecho a enviar procuradores a Cortes, los conflictos políticos también se prodigaron durante las dos primeras décadas del siglo XVI en otras ciudades de segundo rango, donde adoptaron perfiles muy diversos ${ }^{32}$. $Y$, por consiguiente, no vamos a entrar aquí en un análisis particularizado de los mismos, pero sí nos interesa hacer constar que en algunas de ellas, en concreto de las situadas en la meseta, se reprodujeron situaciones que ya hemos constatado en las ciudades con voto en Cortes. Y así, nos consta que en Olmedo los regidores adoptaron entonces una posición muy semejante a la de sus homólogos de Soria, Segovia o Ávila, y trataron de intervenir en la vida política interna del Común de pecheros, para que se eligiesen como procuradores individuos que les fuesen afectos. $\mathrm{Y}$ así lo prueba, por ejemplo, la denuncia presentada en 1515 ante el Consejo Real por el representante de los pecheros de esta villa, acusando a los regidores de haber comenzado a entrometerse a partir del año 1512 en los procesos de nombramiento y elección de los oficiales del Común, que tradicionalmente eran elegidos por los pecheros el primer viernes de cada año, estando reunidos éstos en una iglesia bajo la presidencia del corregidor o su lugarteniente, pero sin que asistiese ningún regidor. Puesto que, según los denunciantes, en los últimos años los regidores habían llegado incluso a negociar con los distintos pecheros en particular

30 Vid. AGS, RGS, VIII-1517. Esta concesión se efectuó en respuesta a las peticiones presentadas por representantes del cabildo de la Iglesia Mayor, de los monasterios, de la Universidad y de las 14 cuadrillas en que se agrupaba la población pechera.

31 Vid. Bonachía Hernando, José Antonio: «La ciudad de Burgos en la época del Consulado», Actas del V Centenario del Consulado de Burgos, Burgos, Diputación Provincial, 1994, pp. 69-146.

32 En las ciudades riojanas, por ejemplo, se desarrollaron importantes conflictos entre los estamentos pechero y ciudadano, que no participan de las mismas características de los conflictos entre oligarquías y dirigentes del Común de pecheros que tuvieron lugar en las ciudades de la Meseta. Vid. Diago Hernando, Máximo: «Conflictos estamentales por el control del gobierno municipal en Logroño a fines del XV y principios del XVI», Cuadernos de Estudios Medievales y CC y TT Historiográficas, 17 (1992), pp. 205-25. Y. «El concejo de Calahorra...» 
con el objetivo de «tomar votos para que sean elegidas las personas que vosotros (es decir, los regidores) queréis, para los tener de vuestra mano»33.

A través dẻ los ejemplos aducidos entendemos que ha podido quedar suficientemente demostrado que durante las dos primeras décadas del siglo XVI tuvo lugar un proceso de intensificación de las demandas de participación en el gobierno urbano desde el Común de pecheros, que provocó una reacción defensiva de los grupos oligárquicos, poco dispuestos a hacer concesiones. Pero en ocasiones la presión llegó a ser tan grande que la «oposición pechera» consiguió arrancar algunas pequeñas concesiones, como, por ejemplo, en Valladolid, donde lograron en 1517 que se les reconociese el derecho a enviar representantes a las sesiones del regimiento, o en Soria, donde también ese año gracias a la actividad desplegada en la Corte por el procurador del Común se logró poner fin a varias décadas de control del corregimiento por Juan Velázquez de Cuéllar, firme aliado de los regidores sorianos.

Estos logros políticos de los pecheros probablemente contribuyeron a abrir en bastantes ciudades castellanas expectativas de cambio, y a convencer a muchos de la viabilidad del proyecto de arrebatar a las oligarquías urbanas el monopolio en el control de las instituciones de gobierno local del que desde hacía tiempo venían disfrutando. Y quizás por ello, a partir de la primavera de 1520 , cuando la rebelión de 'un importante número de ciudades contra el rey Carlos I generó una situación sin precedentes desde el punto de vista institucional, al quedar en suspenso varias instituciones de gobierno clave, como el Consejo Real y los corregimientos, los sectores del Común de pecheros que se habían venido movilizando contra las oligarquías en las décadas previas trataron de aprovechar esta situación de inestabilidad para dar el golpe de fuerza que les permitiese alcanzar en poco tiempo el objetivo por el que venían luchando desde hacía tiempo: derribar el régimen de gobierno oligárquico imperante y sustituirlo por otro basado en el principio de renovación periódica de los oficiales, y que permitiese participar en el ejercicio del poder a un espectro social mucho más amplio ${ }^{34}$.

\section{TRANSFORMACIONES EN LA COMPOSICIÓN DE LAS ASAMBLEAS CONCEJILES DE LAS CIUDADES COMUNERAS DURANTE 1520}

De hecho en los trabajos de investigación hasta ahora dedicados a las Comunidades se ha prestado poca atención al análisis de los conflictos internos que tuvieron lugar en las distintas ciudades en particular entre los diversos grupos que conformaban las sociedades políticas locales, porque siempre se ha

33 AGS, RGS, VI-1515. Provisión dirigida a los oficiales del concejo de Olmedo.

34 Esta tesis es defendida también por VAL VALDIVIESO, $\mathbf{M}^{\mathbf{a}}$. Isabel del: «Aspiraciones y actitudes sociopolíticas. Una aproximación a la sociedad urbana de la Castilla bajomedieval», en BONACHÍA HERNANDO, José Antonio (Coord.): La ciudad medieval, Universidad de Valladolid, 1996, pp. 219 y ss.

Hispania, LXIII/2, núm. 214 (2003) 623-656 
dado preferencia al análisis del enfrentamiento entre la monarquía y las ciudades. Y, por consiguiente, no podemos describir con un mínimo detalle los procesos que propiciaron en cada ciudad la reforma de sus órganos de gobierno local durante los años 1520 y 1521 . Pero en contrapartida un hecho que, con las informaciones hoy por hoy disponibles, ha quedado suficientemente probado es que tales reformas prosperaron en numerosas ciudades. $Y$ resulta poco creíble que se impusiesen con la aquiescencia de todos los sectores de la correspondiente sociedad política local.

Para empezar tenemos constancia de que en unas pocas ciudades el inicio de la revuelta comunera desencadenó un proceso de reforma radical de la asamblea concejil, que contempló la supresión de la figura de los regidores. El ejemplo más notable nos lo proporciona Murcia, donde el triunfo de la Comunidad a principios de agosto de 1520 fue seguido de una inmediata expulsión de la ciudad de los regidores y jurados. Y poco después se aprobó una reforma del régimen de gobierno local que tenía como pieza clave la implantación de oficiales concejiles por elección que tuviesen mandatos anuales, a diferencia de los regidores, que eran oficiales vitalicios y recibían su nombramiento directamente del rey35.

Los acontecimientos ocurridos en Murcia tuvieron, no obstante, un carácter excepcional, y de hecho sólo tenemos noticia de otra ciudad en la que al parecer en un primer momento también fueron expulsados todos los regidores, $\mathrm{y}$, por consiguiente, pasó a estar gobernada por diputados: Aranda de Duero ${ }^{36}$. Pero consideramos poco probable que esta situación se prolongase durante mucho tiempo, ya que esta ciudad pasó pronto a militar en el bando realista, y cabe presumir que a raíz de ello los regidores recuperasen el poder perdido.

En la mayor parte de las ciudades en que triunfó la revuelta comunera un número importante de regidores participaron activamente en la rebelión, y, por consiguiente, no se produjeron fenómenos equiparables al de Murcia, que generasen situaciones de vacío de poder que facilitasen la imposición de reformas radicales en los regímenes de gobierno local. De hecho, dado que en un primer momento fueron los propios regidores los principales incitadores a la rebelión, en muchas ciudades éstos continuaron en sus puestos, y a lo sumo accedieron a que se ampliase la composición de las asambleas concejiles, dando entrada en las mismas, con derecho de voz y voto, a representantes de otros grupos estamentales.

Así ocurrió en la ciudad de Toledo, la principal incitadora de la rebelión, donde los regidores continuaron manteniendo el control de la asamblea concejil durante los primeros meses que siguieron a la expulsión del corregidor a fines de mayo de 1520. Poco a poco, no obstante, conforme se fue dando cabi-

35 OwENS, John B.: Rebelión, monarquía y oligarquía murciana en la época de Carlos $V$, Universidad de Murcia, 1980, pp. 59 y 117.

36 Vid. PÉreZ, Joseph: La revolución de las Comunidades de Castilla (1520-1521), Siglo XXI, Madrid, 1979, p. 510.

Hispania, LXIII/2, núm. 214 (2003) 623-656 
da en dicha asamblea a un número cada vez mayor de personas en representación de las parroquias, los regidores comenzaron a perder capacidad de control sobre la toma de decisiones en la misma. Y, además, a partir del mes de junio empezó a reunirse otra asamblea paralela, la de la Comunidad, a la que se dio el nombre de "congregación", que progresivamente asumió atribuciones a costa de la asamblea concejil tradicional, que se fue reuniendo de forma cada vez más esporádica, hasta quedar finalmente desplazada como principal instancia de gobierno y administración de la ciudad ${ }^{37}$.

Este proceso de sustitución progresiva y no traumática como principal instancia de gobierno local de la asamblea concejil tradicional, controlada en los primeros meses de la rebelión por los regidores comuneros, por la asamblea de la Comunidad, también se dio en otras varias ciudades comprometidas en la causa rebelde, aunque a un ritmo que varió de unas a otras. Por ejemplo en Segovia el proceso fue muy rápido, ya que, según los investigadores que han analizado el caso de esta ciudad, poco después de iniciarse allí la rebelión contra la monarquía los regidores fueron suspendidos de sus funciones, y la tradicional asamblea concejil, constituida por estos oficiales y el corregidor, fue sustituida por una institución de nuevo cuño llamada "consulta», que asumió el desempeño de las funciones de gobierno ejecutivo, nombró a los capitanes de la milicia concejil, gestionó el reclutamiento de la misma y la recaudación de impuestos para la financiación de la guerra, y organizó el proceso de designación de representantes de la ciudad ante la Junta central comunera ${ }^{38}$. Y, aunque a las sesiones de esta "consulta» asistieron varios regidores, no lo hicieron en su condición de tales sino a título meramente personal.

Tras Segovia, otra ciudad en la que al parecer también se impusieron muy tempranamente cambios radicales fue Valladolid, donde, según Joseph Pérez, a partir de agosto de 1520 el antiguo regimiento fue reemplazado por dos comités, uno encargado de los asuntos militares y el mantenimiento del orden, y otro que se ocupaba de los asuntos políticos, en ambos casos constituidos por delegados de las cuadrillas, y presididos por un capitán de la Comunidad, que en un primer momento fue el infante Don Juan de Granada 39 .

Más lentamente evolucionaron los acontecimientos en Madrid, donde los cambios en las instituciones de gobierno local se implantaron poco a poco, siguiendo de cerca las pautas marcadas por la vecina ciudad de Toledo, con la que en todo momento se mantuvieron estrechos contactos. En concreto la tradicional asamblea concejil continuó funcionando con regularidad, tras ser apartados de la misma los regidores que apoyaron al bando realista, aunque se vio considerablemente ampliada al admitirse a sus reuniones dos diputados por

37 Martínez GIL, Fernando: La ciudad inquieta. Toledo comunera 1520-1522, Toledo, 1995, pp. 150-1.

38 Vid. SÁnCHeZ LeÓN, Pablo: op. cit. p. 219.

39 PÉrEZ, Joseph: op. cit. p. 212.

Hispania, LXIII/2, núm. 214 (2003) 623-656 
parroquia, a los que se dio el nombre de "procuradores de las parroquias» ${ }^{40}$. Y, según Carmen Losa Contreras, fueron estos diputados los que en el transcurso del año 1520 se hicieron con el control político de la asamblea concejil, gracias a que asistieron de forma masiva a sus sesiones y mostraron un gran entusiasmo por participar activamente en la toma de decisiones políticas, después de habérseles estado negando durante mucho tiempo la capacidad de hacerlo ${ }^{41}$.

Lo que ocurrió en otras ciudades que se sumaron a la rebelión, accediendo a enviar procuradores a la Junta comunera, lo conocemos con menor detalle, aunque por lo poco que sabemos parece seguro que en todas ellas siguió en funcionamiento la asamblea concejil tradicional, en la que continuaban ocupando un lugar preferente los regidores. En algunas ciudades incluso dicha asamblea continuó siendo presidida por oficiales de la justicia designados por el rey, pero se trató siempre de aquéllas más aferradas a posturas conservadoras, y que finalmente acabaron apartándose del bando comunero, como Burgos, Soria, o Cuenca. Pero en todas ellas dicha asamblea quedó considerablemente ampliada.

En concreto en Zamora el ayuntamiento continuó bajo control de los elementos conservadores, y presidido por el corregidor nombrado por el rey hasta el mes de septiembre de 1520 . A comienzos de ese mes, el día tres, irrumpieron en la sesión concejil diez diputados de la Comunidad, y pocas semanas después el corregidor dejó de presidir las sesiones de ayuntamiento para ser sustituido por un alcalde designado por la Comunidad. Y en adelante los regidores poco a poco fueron siendo desplazados por los diputados de las parroquias, que podían participar en las deliberaciones del ayuntamiento con voz y voto, hasta el punto de que a la sesión de 9 de noviembre ya sólo asistió un regidor ${ }^{42}$.

En León sabemos que la asamblea concejil quedó considerablemente ampliada debido a que los documentos expedidos por la corporación de gobierno local durante los meses de la revuelta se otorgaron en nombre de los «regidores, caballeros, hidalgos y diputados de los señores de la iglesia mayor de la dicha ciudad y de la honrada comunidad de la ciudad de León» ${ }^{43}$.

En Ávila también nos consta que los regidores debieron compartir responsabilidades de gobierno con representantes de otros sectores de la sociedad po-

40 Losa CONTRERAS, Carmen: El concejo de Madrid en el tránsito de la Edad Media a la Edad Moderna, Dykinson, Madrid, 1999, pp. 43-4.

41 LOSA CONTRERAS, Carmen: op. cit. pp. 623-4.

42 FernándeZ Álvarez, Manuel: «La Zamora comunera en 1520», Studia Historica. Historia Moderna, 3 (1983), pp. 7-28. Y DANVILA Collado, Manuel: Historia crítica y documentada de las Comunidades de Castilla, vol. II, p. 116 (Esta obra la citamos por la edición del Memorial Histórico Español, indicando el número de orden del volumen dentro de los 6 que abarca la obra de Danvila en esta edición. El volumen I corresponde al XXXV del Memorial Histórico Español, y así sucesivamente hasta el VI, que corresponde al XL).

43 Vid. DíAZ-JimÉnEZ y MOLLEDA, Eloy: Historia de los comuneros de León y de su influencia en el movimiento general de Castilla, Madrid, 1916, pp. 227-8. El cabildo de la catedral ya en febrero de 1520 otorgó poder a dos canónigos para que acudiesen a entender en los asuntos de la comunidad local. Íbid. pp. 125 y 167. 
lítica local, y en concreto con clérigos y, sobre todo, con pecheros representantes de las cuadrillas, todos los cuales se integraron en un nuevo órgano asambleario al que se dio el nombre de «congregación» ${ }^{44}$.

También en Soria, a pesar de las grandes reticencias que mostró esta ciudad a sumarse a la rebelión comunera, la presión popular, eficazmente canalizada por los sectores dirigentes del Común de pecheros, forzó a la oligarquía a admitir la introducción de cambios en la composición de las asambleas concejiles, que permitiesen una mayor participación del conjunto de la población en la toma de decisiones. Y ello a pesar de que allí ya venían participando regularmente en dichas asambleas, además del oficial de la justicia y de los regidores, tres procuradores de los doce linajes de hidalgos, un procurador del Común de la ciudad, y un fiel y un procurador general en representación de los vecinos de las aldeas de la Tierra.

Así nos lo confirma en primer lugar una carta que esta ciudad dirigió a la de Valladolid el 4 de septiembre de 1520, la cual fue otorgada en nombre de los señores caballeros, concejo, justicia, regidores y procuradores de la Comunidad de Soria y su Tierra, cuando otras cartas que se habían enviado durante el mes de agosto habían sido otorgadas sólo en nombre de los «caballeros y regidores $»^{45}$. Pero todavía más reveladora resulta la fórmula empleada en la carta dirigida el 5 de octubre de 1520 por el concejo soriano al comendador Aguilera, el que había sido su procurador a las Cortes de Santiago, que fue otorgada en nombre de los «caballeros, concejo, justicia, regidores y diputados de todos los estados de la noble ciudad de Soria»" ${ }^{46}$.

Dado que no se han conservado las actas de concejo de estos años no disponemos de pruebas seguras que demuestren que representantes del estamento eclesiástico asistiesen regularmente a las sesiones concejiles a partir del verano de 1520 , como consta que ocurrió en otras ciudades. Pero consideramos muy sintomático que uno de los cuatro procuradores que representaron a la ciudad

44 Se hacen bastantes referencias a esta «Congregación» en los libros de actas del cabildo de la catedral de Ávila de 1520, editados por SÁNCHEZ SÁNCHEZ, Andrés: Resumen de Actas del Cabildo Catedralicio de Ávila (1511-1521), tomo I, Fuentes Históricas Abulenses, 23, Ávila, 1995. Por ejemplo en la sesión del cabildo de 14-VIII-1520 se decidió revocar el poder que éste había otorgado anteriormente al deán, al licenciado Escudero y al arcediano de Bonilla «para asistir en la Congregaçión, que se avía de hazer e hizo en la dicha çibdad con los Regidores e Comunydad della» (Doc. $n^{\circ}$. 509). También se aplicó, no obstante, el nombre de «Congregación» a la Junta de ciudades con voto en Cortes que a iniciativa de Toledo se comenzó reuniendo en Ávila, y poco después pasó a fijar su sede en Tordesillas. Así en el acta de 18-VIII-1520 se hace referencia al hecho de que se había prohibido bajo ciertas penas al deán y al arcediano de Ávila «que no entrasen, ny asistiesen en la Congregaçión de los Regidores e Comunydad desta çibdad e tanbién les prohibieron que no entren en la Congregaçión de los procuradores de las çibdades, que se haze en esta çibdad». (Doc. $\mathbf{n}^{\circ}$. 512).

45 Los textos de estas cartas están publicados en Higes, Víctor: «Soria en época de las Comunidades (Nuevas aportaciones documentales)», Celtiberia, 11 (1956), pp. 109-117.

46 Un ejemplo lo tenemos en la carta que dirigió la ciudad de Soria al comendador Aguilera el 5 de octubre de 1520, publicada en Danvila, II, pp. 429-30.

Hispania, LXIII/2, núm. 214 (2003) 623-656 
en la Junta de Tordesillas fuese un clérigo, el deán de la colegiata, Hernán Yáñez de Morales. Y, en cualquier caso, sí tenemos constancia de que los pecheros de la ciudad consiguieron incrementar apreciablemente su cuota de participación en dicha asamblea, ya que además del procurador del Común pudieron acceder a ella otros tres diputados ${ }^{47}$.

Otra ciudad que, como Soria, destacó por su tibio compromiso comunero, fue Cuenca. Y a pesar de ello también allí se introdujeron en el transcurso del año 1520 importantes reformas en el régimen de gobierno local, que podemos analizar con un mayor detalle gracias a haberse conservado todos los libros de actas concejiles de este año y del siguiente. Antes de estallar la revuelta comunera en esta ciudad sólo podían asistir a las sesiones de concejo, además de los oficiales de la justicia y los regidores, un procurador síndico de la ciudad, un procurador de la Tierra, y un procurador del estamento de caballeros y escuderos, pero no estaba contemplada la figura institucional del procurador del Común de pecheros de la ciudad. Y por ello representó un acontecimiento sumamente novedoso cuando el día 3 de julio de 1520 se presentó en la asamblea de concejo un tal Miguel Cantero, quien manifestó haber sido elegido como procurador por la Comunidad, y a continuación procedió a jurar conforme a derecho que usaría bien y fielmente de dicho oficio. Más adelante éste declaró que su nombramiento como tal procurador se había llevado a cabo en cumplimiento de una provisión por la que los Reyes Católicos habían facultado a la ciudad de Cuenca para poder elegir dicho oficial, y se había realizado antes de que en la ciudad «se alterase la Comunidad», por lo cual no había guardado relación ninguna con dichas alteraciones ${ }^{48}$. Según el punto de vista de los regidores, sin embargo, su elección se había llevado a cabo de forma irregular, puesto que sólo había intervenido en ella el procurador síndico, Alonso de la Parra, junto con otras personas, y por lo tanto se había dejado de observar lo que se disponía en la provisión de los Reyes Católicos, que ordenaba que fuese nombrado por la ciudad junto con el justicia.

Pero, en cualquier caso, en aquel momento ni los regidores ni el teniente de corregidor que presidía la reunión concejil, el licenciado Montiel, tuvieron inconveniente en consentir que prestase juramento como procurador de la Comunidad, y, además, a partir de entonces comenzó a asistir regularmente a todas las asambleas. Y sólo bastantes meses después, cuando la rebelión comunera había sido aplastada en toda Castilla, justificaron los regidores conquenses su actitud permisiva alegando que en aquellos momentos la ciudad «andaba alterada», y que por esta razón se había considerado conveniente transigir para contribuir a la pacificación de la misma ${ }^{49}$.

47 Vid. Diago Hernando, Máximo: «Las ciudades castellanas contra Carlos I...»

48 Declaraciones registradas en el acta de la sesión de $18-\mathrm{V}-1521$.

49 Estas declaraciones de los regidores se registran en el acta de la sesión de 7-VI-1521. Según las mismas en aquella ocasión el regidor Juan de Ortega quiso contradecir la entrada del procurador al ayuntamiento, pero el licenciado Montiel le recomendó que no lo hiciese porque al estar el procurador en el ayuntamiento se podía pacificar la ciudad. 
Queda fuera de duda, por tanto, que a comienzos del mes de julio de 1520 la presión de los sectores populares obligó al grupo oligárquico conquense a consentir que representantes de dichos sectores pasasen a participar en la toma de decisiones en los órganos de gobierno local. Puesto que, en efecto, a partir de entonces, además del procurador de la Comunidad, otros muchos oficiales que representaban a los sectores populares conquenses pasaron a asistir con regularidad a las sesiones concejiles, y en concreto en una primera fase un jurado por cada una de las collaciones, y más adelante otros oficiales que respondían a los nombres de diputados, letrado y pesquisidor de la Comunidad ${ }^{50}$. Pero es cierto que en la mayor parte de las sesiones, tanto del mes de julio como del mes de agosto, los regidores efectuaron reiteradamente protestas formales para que quedase constancia de que ellos no aprobaban la presencia de estos representantes de la Comunidad en los ayuntamientos, y que por lo tanto se producía contra su voluntad.

Fue por lo tanto una situación bastante singular la que se vivió en las asambleas de concejo conquenses a partir del verano de 1520 , debido a que los regidores, para no verse desbordados por la avalancha popular, que amenazaba con hacerles perder el control de los órganos de gobierno local, consintieron de facto en dar entrada a los mismos a los representantes de los sectores populares, aunque sin hacer concesiones en el terreno de los principios, en la esperanza de que, una vez desaparecido el peligro de subversión que de forma tan apremiante se cernía sobre la ciudad y sobre toda Castilla en el verano de 1520 , todo podría volver a la normalidad.

En cualquier caso interesa recalcar que la ampliación del ayuntamiento conquense, para dar cabida en él a numerosos representantes de los sectores populares, fue compatible con el mantenimiento de la figura institucional del corregidor de nombramiento regio. Puesto que Cuenca, a diferencia de la mayor parte de las ciudades comuneras, sólo dejó de estar gobernada por un oficial de la justicia designado por la monarquía en el breve período de tiempo que fue del 20 de julio al 1 de agosto. Lo cual nos confirma que en esta ciudad para los sectores procomuneros tuvo absoluta prioridad el objetivo de reformar las instituciones de gobierno local frente al de establecer sobre nuevas bases las relaciones de la sociedad política conquense con la monarquía. Y, probablemente porque eran conscientes de este hecho, a finales de noviembre de 1520 los propios gobernadores designados por el rey facultaron por medio de una provisión a cada una de las collaciones de Cuenca para eligir todos los años un jurado, con derecho a estar presente en las sesiones del regimiento, aunque sin voz ni voto, para que si algo se acordaba en ellas que estimasen que causaba

so Desempeñó el oficio de pesquisidor, nombrado por la Comunidad, Juan de la Bachillera, identificado a veces en los libros de actas como «pesquisidor para entender en las cosas que en la ciudad sucedieren».

Hispania, LXIII/2, núm. 214 (2003) 623-656 
agravio a la ciudad y a su Tierra lo pudiesen contradecir, tomándolo por testimonio ante el escribano del concejo ${ }^{\text {s1 }}$.

Tras quedar alejado el peligro de subversión del conjunto del reino de Castilla como consecuencia de la derrota comunera en Villalar, la capacidad de presión de los sectores populares conquenses quedó muy mermada. Y entonces los regidores aprovecharon para contraatacar y recuperar su capacidad de control exclusivo de los resortes del poder local, que habían perdido en julio de 1520 , al tener que consentir que asistiesen a las sesiones del regimiento el procurador y los demás representantes de la Comunidad. En concreto en las primeras sesiones de consistorio celebradas en junio de 1521, estos oficiales, exigieron formalmente al oficial de la justicia que presidía que se dejase de admitir a dichas sesiones al procurador de la Comunidad y a los jurados de las parroquias. Y esta solicitud fue inmediatamente atendida, ya que el día 8 de junio el escribano del ayuntamiento procedió a notificar al procurador de la Comunidad, Miguel Cantero, que en adelante le quedaba prohibida la entrada en el ayuntamiento, so pena de $50.000 \mathrm{mrs}$., porque así se lo había ordenado el teniente de corregidor, hasta que se determinase por vía de justicia si le asistía el derecho a poder entrar. Y similares notificaciones debieron recibir los jurados, puesto que, en adelante, ni éstos ni el procurador volvieron a hacer acto de presencia en las sesiones de consistorio, a las que sólo asistieron a partir de entonces, junto a regidores y oficial de la justicia, los procuradores que ya habían tenido reconocido derecho de asistencia antes del verano de 1520 , es decir el síndico de la ciudad, el de caballeros y escuderos y el de la Tierra.

Por fin, un tercer ejemplo muy ilustrativo de ciudad que apenas se comprometió en la rebelión contra la monarquía, pero que, sin embargo, sí introdujo importantes cambios en la composición de su principal órgano de gobierno local en el transcurso del año 1520, nos lo proporciona Jaén. En efecto, ésta fue la única de las cuatro ciudades andaluzas con voto en Cortes en que, aunque por breve espacio de tiempo, triunfó la rebelión comunera. Fue a raíz de un motín popular que tuvo lugar el día 19 de agosto de 1520, tras el cual se procedió a arrebatar las varas de la justicia a los oficiales que las tenían en nombre del rey, y a designar en su lugar por votación popular cuatro alcaldes ordinarios y un nuevo alguacil mayor. Y desde aquel momento la composición de la asamblea concejil pasó a quedar también considerablemente ampliada, ya que a los oficiales que hasta entonces venían formando parte de la misma, que, además de los de la justicia, eran los regidores, el personero y los jurados, se vino a sumar un importante número de diputados de la Comunidad, elegidos a razón de tres o cuatro por cada collación, a los cuales, no obstante, se les reconoció voz pero no voto ${ }^{52}$.

51 Provisión fechada en Medina de Ríoseco, 27-XI-1520, presentada en sesión de consistorio de 18-XII-1520. La concesión no se efectuaba a perpetuidad sino por el tiempo «quanto fuere nuestra merced y voluntad».

52 Análisis pormenorizado de los hechos en Porras Arboledas Pedro A.: La ciudad de Jaén y la revolución de las Comunidades de Castilla (1500-1523), Jaén, 1993. 
Desde entonces la ciudad mantuvo durante varias semanas una actitud calculadamente ambigua, pues inició algunos contactos con la Junta de Tordesillas pero al mismo tiempo evitó la ruptura con los representantes del poder real. Muy pronto, sin embargo, optó por decantarse decididamente del lado realista. Pero a pesar de ello se mantuvieron en vigor los cambios constitucionales introducidos a partir del día 19 de agosto, y los propios gobernadores cuando concedieron carta de perdón a la ciudad en enero de 1521 evitaron hacer cualquier tipo de referencia a los mismos, contribuyendo así de facto a su consolidación.

De hecho, sin embargo, se trató de una simple tregua, en espera de que se normalizase la situación política en el conjunto del reino, o al menos en toda Andalucía. Pues, a mediados de marzo de 1521, una vez que tomó posesión de su cargo el nuevo corregidor enviado por los gobernadores, Francisco Sedeño, rápidamente fue restaurado el ordenamiento constitucional vigente antes del 19 de agosto, ya que éste no se limitó a ordenar el cese de los oficiales de la justicia que habían sido nombrados por la ciudad en sustitución de los oficiales del rey, sino que también disolvió la Comunidad y prohibió a sus diputados que continuasen asistiendo a los cabildos ${ }^{53}$.

Los ejemplos analizados no dejan lugar a dudas, por tanto, de que el estallido de la revuelta comunera propició en numerosas ciudades castellanas una sensible ampliación en la composición de sus asambleas de gobierno, que durante las dos primeras décadas del siglo habían sido férreamente controladas por los regidores, quienes en algunos casos habían sido los únicos oficiales representantes de la sociedad política local que habían tenido acceso a las mismas, junto al oficial de la justicia designado por el rey. En las ciudades más comprometidas con la causa rebelde esta ampliación derivó pronto en una radical transformación del régimen de funcionamiento de dichas asambleas, debido a que poco a poco los regidores, a pesar de que bastantes de ellos habían sido en un primer momento los promotores de la rebelión, fueron perdiendo el control de las mismas en beneficio de los elementos más radicales, procedentes tanto del Común de pecheros como de los grupos exentos de titulados universitarios y clérigos regulares de las Órdenes Mendicantes.

Por el contrario en las ciudades que adoptaron una postura más conservadora, y poco a poco fueron retirando su apoyo a la Santa Junta comunera, esta ampliación de las asambleas de gobierno urbano no dio lugar a una desnaturalización de las mismas, sino que éstas siguieron en gran medida bajo el control de los regidores. Pero el criterio de admitir a dichas asambleas a una amplia representación de la sociedad política local se siguió respetando en estas ciudades incluso después de haberse producido la ruptura con la Santa Junta, como bien demuestra el caso de Cuenca, y mejor aún todavía el de Jaén, que mantuvo unas relaciones muy distantes y ambiguas con aquélla, y muy pronto se decantó por declarar su plena obediencia al poder real.

53 Íbid. pp. 106-7. La llegada de este corregidor a Jaén se produjo el 18 de marzo de 1521. 


\section{Potenciación DE LOS Oficios DE RENOVACIÓN ANUAL: JURADOS Y DIPUTADOS}

Uno de los objetivos principales del programa político de los comuneros para el gobierno de las ciudades castellanas fue conseguir la sustitución de. los oficiales vitalicios por otros que tuviesen mandatos anuales y pudiesen ser elegidos por la propia sociedad política local. Este planteamiento ya había sido defendido en el plano teórico por algunos intelectuales castellanos del siglo XV como el profesor salmantino Fernando de Roa, quien había mostrado abiertamente su preferencia por que los oficios de gobierno no tuviesen carácter vitalicio y las personas que los desempeñaban fuesen designadas mediante elección $^{54}$. Y en un alto porcentaje de las ciudades de la Europa bajomedieval los oficiales que desempeñaban las principales tareas de gobierno y administración respondían a este modelo propiciado por los comuneros, y no al que se había consolidado en los principales núcleos urbanos castellanos a partir de mediados del siglo XIV, en virtud de las reformas introducidas por Alfonso XI. De modo que, sin ir más lejos, en la propia Corona de Aragón la gran mayoría de sus ciudades se gobernaban por oficiales que se renovaban con periodicidad anual, y que en la mayor parte de los casos no podían proceder del grupo noble, porque el disfrute de esta condición privilegiada era incompatible con la pertenencia a la comunidad política urbana.

El proyecto de reforma de las instituciones de gobierno local de los comuneros no resultaba por lo tanto desde este punto de vista "revolucionario", ya que en última instancia se limitaba a propiciar para las ciudades castellanas los modelos de gobierno que en aquellos momentos se encontraban más difundidos entre las ciudades europeas. Pero sí conllevaba una radical modificación de los presupuestos sobre los que hasta entonces se había venido fundamentando el ejercicio del poder en las ciudades castellanas, que implicaban una concepción de los oficios públicos como prebendas utilizadas por la monarquía para premiar a sus servidores, por lo cual se les consideraba susceptibles incluso de ser convertidos en un elemento más del patrimonio de quien los desempeñaba, que podía ser transmitido a sus descendientes.

La declarada predilección mostrada por los comuneros hacia los oficios no vitalicios les llevó a potenciar los oficios de diputados de las parroquias o cuadrillas, para que ofreciesen un fuerte contrapeso no sólo frente a los regidores, sino también incluso frente a los propios jurados en aquellas ciudades en las que éstos se habían convertido también en oficiales vitalicios. Así ocurrió en Toledo, donde, desde su creación en tiempos de Juan II, el oficio de jurado había tenido carácter vitalicio, por lo cual los comuneros propiciaron su sustitución por diputados que desempeñasen el cargo por períodos de un año, y que

54 Sobre la obra de Fernando de Roa Vid. Castillo Vegas, Jesús Luis: Política y clases medias. El siglo XV y el maestro salmantino Fernando de Roa. Universidad de Valladolid, 1987.

Hispania, LXIII/2, núm. 214 (2003) 623-656 
además fuesen elegidos directamente entre los parroquianos de cada collación. $Y$ buena prueba de la animadversión que mostraron los comuneros toledanos hacia los jurados vitalicios nos la proporcionan las declaraciones de uno de estos jurados, Juan Sánchez de San Pedro, durante el proceso contra Juan de Gaitán, en las que entre otras cosas manifestó, refiriéndose a lo ocurrido en Toledo entre los años 1520 y 1522 , que

«todas las parroquias de la dicha ciudad hicieron diputados para sus propósitos, sin tomar parecer de ninguno de los jurados de dicha ciudad, sino antes contra ellos y contra sus oficios...y que mandaban en sus parroquias que no hiciesen jurados conforme a los privilegios y uso y costumbre, salvo que hubiese diputados como los había o jurados añales, y no de otra manera» ${ }^{55}$.

Ciertamente la figura de los diputados de las cuadrillas o parroquias no fue creada ex novo en las ciudades comuneras en el transcurso del año 1520 sino que ya venía existiendo desde hacía tiempo, con éste u otros nombres, en numerosas ciudades. Pero en la mayor parte de los casos estos oficiales no habían tenido reconocida capacidad para el desempeño de actividades políticas de relevancia, y sus funciones habían quedado circunscritas a colaborar en las tareas de recaudación de impuestos en el marco concreto de la cuadrilla en la que habían sido elegidos. Sólo en algunas pocas ciudades los diputados de parroquias, en otras ocasiones llamados cuadrilleros, pudieron acceder con regularidad con anterioridad a 1520 a las asambleas concejiles, y desempeñar en ellas funciones políticas de cierta relevancia. Pero da la coincidencia de que habitualmente en las ciudades en que se dio este fenómeno, como es el caso de la mayoría de las riojanas, los propios regidores eran oficiales que se designaban por períodos de un año, y por lo tanto las diferencias que separaban a los diputados de estos oficiales, que eran los de máximo rango en las asambleas concejiles castellanas por detrás de los oficiales de la justicia, eran pequeñas, hasta el punto de que muchos individuos desempeñaron en diferentes momentos de sus carreras alternativamente, y sin orden cronológico de preferencia, los dos oficios ${ }^{56}$.

s5 Tomamos la cita de ARANDA PÉREZ, Francisco Javier: Poder y poderes en la ciudad de Toledo. Gobierno, sociedad y oligarquías urbanas en la Edad Moderna, Universidad de Castilla-La Mancha, Cuenca, 1999, p. 64.

s6 Sobre los diputados de parroquias en Calahorra Vid. Diago Hernando, Máximo: «El concejo de Calahorra...». Se demuestra que en esta ciudad las mismas personas ejercieron indistintamente los oficios de regidor, que eran cuatro por año, y de diputado, que eran ocho por año. En Santo Domingo de la Calzada los barrios estaban representados en la asamblea concejil por dos oficiales diferentes, los cuadrilleros y los jurados. Vid. Diago Hernando, Máximo: «Santo Domingo de la Calzada en la Baja Edad Media. Aspectos de su organización político-institucional», Berceo, 130 (1996), pp. 116-7. Más datos sobre presencia de diputados en las 'asambleas concejiles de ciudades riojanas en Goicolé Julí́N, Francisco Javier: «Concejos urbanos en la Rioja Alta a fines del Medievo: Aspectos institucionales y políticos», HID, 26 (1999), pp. 233-53. 
En las grandes ciudades castellanas, donde los oficios de regidores tenían carácter vitalicio, los diputados de las parroquias no tuvieron acceso regular a las asambleas concejiles, salvo en circunstancias excepcionales, como las que se vivieron, por ejemplo, en Cuenca en 1465. Puesto que sabemos, en efecto, que en esta ciudad en una asamblea multitudinaria que tuvo lugar el 26 de marzo de dicho año a la que asistieron el procurador síndico y de los pecheros, los cuadrilleros y cerca de un centenar de vecinos se acordó que cada cuadrilla procediese a designar tres o cuatro diputados pecheros que junto con los cuadrilleros pudiesen reunirse con los oficiales de la justicia y los regidores para tratar los asuntos del gobierno de la ciudad, verificándose aquel mismo día, pocas horas después, la elección de dichos diputados ${ }^{57}$. Fue una situación excepcional, que probablemente no se volvió a repetir en Cuenca hasta el año 1520, y no deja de resultar sintomático que precisamente en una de las asambleas concejiles que tuvieron lugar aquel año 1465 , a comienzos de septiembre, se decidiese elevar una proposición al rey para que en adelante los oficios de regidores fuesen en la ciudad de renovación anual en lugar de vitalicios ${ }^{58}$.

Dejando a un lado casos excepcionales como el que acabamos de mencionar, que tuvo lugar en un momento coyuntural especialmente crítico, los diputados de cuadrillas o parroquias no tuvieron acceso a las asambleas concejiles ordinarias de las principales ciudades castellanas, sino a lo sumo de vez en cuando a algunas asambleas extraordinarias, a las que se les podía convocar para consultar con ellos sobre alguna toma de decisión importante, o que requería de un amplio consenso. Y en concreto tenemos constancia de que así se acostumbró a hacer en Burgos durante el reinado de los Reyes Católicos ${ }^{59}$. Pero en estas ocasiones estos oficiales sólo desempeñaron una función consultiva, en claro contraste con lo que había ocurrido en la propia ciudad de Burgos durante el reinado de Enrique IV, cuando los diputados que representaron a la Comunidad de pecheros en las asambleas de ayuntamiento a partir de 1465 habían tenido voz y voto ${ }^{60}$.

En el transcurso del año 1520 , sin embargo, enlazando con las prácticas que tímidamente se habían introducido en ciudades como Burgos o Cuenca en los momentos más críticos del reinado de Enrique IV, y que tal vez entonces estuvieron mucho más difundidas de lo que hasta ahora sabemos, se reivindicó para los diputados de las cuadrillas o parroquias el derecho a una participación activa en la toma de decisiones en las asambleas de concejo, donde como con-

57 JARA Fuente, José Antonio: op. cit. p. 128.

58 Íbid. p. 130.

59 Sobre la celebración en Burgos de ayuntamientos de concejo ampliados, en los que participaban procuradores de las vecindades o cuadrillas, Vid. BONACHÍA HERNANDO, José Antonio: «La ciudad de Burgos...»

60 Vid. Pardos Martínez, Julio A.: «Constitución patricia y comunidad en Burgos a finales del siglo XV (Reflexiones en torno a un documento de 1475)", en La ciudad bispánica durante los siglos XIII al XVI, Universidad Complutense, Madrid, 1985, pp. 545-580. 
secuencia podían convertirse fácilmente en el grupo más influyente, ya que constituían con diferencia el más numeroso. Pero, por supuesto, este objetivo no se alcanzó en todas las ciudades comuneras por igual, pudiéndose advertir que aquéllas que más avances efectuaron hacia su plena consecución fueron las que más se comprometieron con la causa rebelde hasta el final, ya que en ellas los diputados de las parroquias reunidos en su asamblea llegaron a controlar los principales resortes del poder local. Y así ocurrió, por ejemplo, en Toledo, como bien ponen de manifiesto las siguientes declaraciones del jurado Juan Sánchez de San Pedro en el proceso contra Juan de Gaitán, manifestando que «todas las parroquias de la dicha ciudad hicieron diputados para sus propósitos...y que de esta manera hicieron su congregación y tenían su escribano y gobernaban la dicha ciudad sin que ningún regidor ni jurado ni caballero ni otra persona de buena intención entendiese entre ellos, y que de allí mandaban hacer fieles ejecutores y otros oficios de la dicha ciudad, y que lo que ellos mandaban se hacía y ponía por obra» ${ }^{6}$.

Por el contrario en las ciudades con orientación política más conservadora, que pronto dejaron de prestar su apoyo a la Santa Junta comunera, la capacidad de los diputados por influir sobre la toma de decisiones en el ámbito local fue siempre muy limitada, y además declinó de forma muy rápida conforme avanzó el año 1521. Y así podemos constatar que ocurrió, por ejemplo, en Jaén, Soria o Cuenca.

Por otro lado también interesa hacer constar que la potenciación de la figura institucional de los diputados de cuadrillas por los comuneros fue consecuencia de la necesidad que desde un primer momento se les planteó a éstos de buscar una alternativa a las asambleas multitudinarias para articular la participación en la vida política del grueso de la población urbana de una forma eficaz, ya que de mantenerse dichas asambleas como pieza clave del entramado institucional para el gobierno de las ciudades se corría el peligro de que la vida política en ellas derivase hacia la anarquía. Y así lo demuestra la carta que la Comunidad de Toledo envió a la de Madrid, proponiéndole que, para salvar los inconvenientes que se seguían de que en los ayuntamientos hubiese gran tumulto de gente, se procediese a elegir por cada parroquia dos diputados, que se reuniesen al menos una vez por semana para acordar las cosas que conviniese

61 Tomamos la cita de ARANDA PÉREZ, Francisco Javier: op. cit., p. 64. Información adicional sobre la figura de los diputados de parroquias toledanos en las declaraciones del prior de la Orden Militar de San Juan de Jerusalén contenidas en los capítulos que éste otorgó a dicha ciudad en octubre de 1521:»Por cuanto la dicha ciudad dice que después de los dichos movimientos ha habido y hay congregaciones de diputados añales de las parroquias, que es que cada parroquia ha de elegir y elige dos diputados, y los diputados de todas las parroquias juntos en su congregación eligen tres procuradores generales del pueblo de los tres estados de caballeros y ciudadanos y oficiales, de cada estado el suyo, y escribano de congregación, lo cual todo se hace cada año por el mes de abril; y hacen su congregación los dichos diputados y procuradores generales cadañeros y con su escribano...». DANVILA, IV, pp. 573-86. 
hacer para el bien, pacificación y gobierno de la ciudad, y una vez tomados sus acuerdos presentasen a continuación sus propuestas al ayuntamiento para que se llevasen a la práctica ${ }^{62}$.

\section{UNA NUEVA FIGURA INSTITUCIONAL: LA COMUNIDAD}

A la hora de reconstruir la historia político-institucional de las ciudades castellanas en los años 1520 y 1521 uno de los principales problemas que se plantea radica en la caracterización de una institución que se menciona con frecuencia en los documentos, la Comunidad, cuyas atribuciones no siempre resultan fáciles de deslindar respecto de las del ayuntamiento de concejo, sobre todo en aquellos casos en que este ayuntamiento escapó al control de los regidores. Ya indicamos que en bastantes ciudades rebeldes la asamblea de la Comunidad terminó por imponerse como la principal instancia de ejercicio del poder en el ámbito local, por encima del ayuntamiento de concejo, que entró en un proceso de fuerte decadencia. Pero este proceso resulta muy difícil de reconstruir en detalle por falta de documentación, y, por tanto, siguen planteadas muchas dudas sobre el alcance que efectivamente tuvo el desplazamiento de una asamblea por la otra.

Dejando a un lado esta cuestión, que ya hemos abordado suficientemente al dar cuenta de los procesos de ampliación de las asambleas de gobierno local en los años 1520 y 1521, interesa que ahora nos centremos en la caracterización de la institución de la Comunidad propiamente dicha en los ámbitos locales, pues entendemos que la misma constituyó la aportación más novedosa del movimiento comunero desde el punto de vista de la historia institucional.

En primer lugar hay que destacar que la institución de la Comunidad que se puso en funcionamiento en muchas ciudades castellanas en el año 1520 presentaba como principal rasgo novedoso que la pertenencia a la misma se formalizaba a través de un juramento prestado de forma solemne por todos sus miembros, quienes a través de él se comprometían a su defensa. Y ésta era una práctica radicalmente novedosa para los vecinos de las ciudades castellanas, puesto que en éstas durante los siglos bajomedievales apenas se había recurrido a la utilización del juramento como principio vertebrador del cuerpo político urbano ${ }^{63}$, de manera que en ellas no se contempló la necesidad de exigir al con-

62 Publica la carta Domingo Palacio, T.: Documentos del Arcbivo de la Villa de Madrid, t. IV, Madrid, 1906, pp. 345-7.

63 GutiérREZ Nieto, J.I.: en «Semántica...» cita diversos ejemplos que prueban que los vecinos de determinadas ciudades castellanas se juramentaron para la defensa de unos precisos objetivos. Se trató, no obstante, de acciones aisladas, que no conllevaron el que la exigencia del juramento se incorporase a los usos constitucionales arraigados en los ámbitos urbanos, y muy en especial en los siglos XIV y XV, cuando se consolidaron los regimientos. Por el contrario en esta época el juramento sí llegó a desempeñar un importante papel como elemento vertebrador de las ligas de ciudades, conocidas con el nombre de Hermandades. 
junto de los vecinos la prestación de un juramento de fidelidad al sistema político urbano, que conllevase el compromiso de preservarlo, en claro contraste con la práctica habitual en las ciudades de otros ámbitos europeos, como Alemania, donde la prestación del juramento era un elemento básico sobre el que se sustentaba la comunidad política urbana ${ }^{64}$.

En Castilla, desde que Alfonso XI instauró el regimiento, los principales oficiales de gobierno urbano desempeñaron sus funciones no en calidad de delegados de una comunidad de personas juramentadas, ante la que tenían que rendir cuentas, sino como oficiales al servicio del rey, que recibían su nombramiento directamente de éste. Puesto que, aunque los procedimientos seguidos para regular el acceso al oficio de regidor variaban apreciablemente de unas ciudades a otras, en todas aquéllas en que este oficio tenía carácter vitalicio siempre correspondía al rey efectuar su nombramiento mediante la expedición de una real provisión, tras la presentación de la cual en sesión de ayuntamiento podía el designado tomar posesión de su oficio. Y sólo en aquellas ciudades en que el oficio de regidor era de renovación anual dejaba de observarse esta formalidad.

Al convertir a la ceremonia de prestación de juramento de fidelidad colectivo en una condición «sine qua non» para el establecimiento de la Comunidad, los sectores radicales del movimiento comunero buscaron deliberadamente por lo tanto la ruptura con una tradición clave del modelo político vigente en las ciudades castellanas. Y fue la ciudad de Toledo la que marcó el camino a las demás, al organizar el día 14 de junio de 1520, festividad del Corpus Christi, una solemne ceremonia de prestación de juramento en el marco privilegiado de la catedral, donde lo prestaron en concreto los caballeros y otras personas principales, mientras que el resto de los vecinos lo hacían en sus correspondientes iglesias parroquiales ante el cura párroco $0^{65}$. Y a imitación del ejemplo de esta ciudad pionera, ceremonias semejantes se repitieron después en otras muchas ciudades en las semanas siguientes.

En segundo lugar, esta institución de la Comunidad que se puso en funcionamiento tras las ceremonias de prestación de juramento durante los meses del verano de 1520 , a pesar de que llevaba el mismo nombre que el órgano de representación del estamento pechero, al que con frecuencia también se aplicó el nombre de Común, que nosotros hemos preferido utilizar siempre al referirnos a él para evitar confusiones, presentó notables diferencias con respecto a esta institución de carácter estamental, que ya había alcanzado un gran desarrollo en diversas ciudades durante el siglo XV y en las primeras décadas del XVI. Pues en la Comunidad se dio cabida a individuos procedentes de todos los estamentos, y no sólo del pechero, aunque sin duda los pertenecientes a éste

64 Vid. EBEL, Winfried: Der Bürgereid als Geltungsgrund und Gestaltungsprinzip des deutschen Mittelalterlichen Stadtrechts, Weimar, 1958. También DiAGo HeRnANDO, Máximo: «Las ciudades en Castilla y en el imperio alemán (Análisis comparativo de su perfil jurídico)», Anuario de Historia del Derecho Español, (1995), pp. 1037-1070.

6s MARTínez GiL, Fernando: op. cit. p. 152.

Hispania, LXIII/2, núm. 214 (2003) 623-656 
constituían mayoría en su seno. Por lo cual la puesta en funcionamiento de esta institución puede ser considerada como una vía de búsqueda de la superación de las divisiones estamentales que desde mediados del siglo XIV habían impedido que en Castilla se consolidase un auténtico «estamento ciudadano» que, al igual que en otros ámbitos europeos, agrupase a toda la población avecindada en los núcleos urbanos, con excepción del clero, y aspirase a participar en la vida política del reino en representación del conjunto de la población ciudadana, defendiendo unos intereses distintos a los de la nobleza ${ }^{66}$.

Consiguientemente, también desde esta perspectiva el movimiento comunero daba otro paso más en la línea de conseguir una transformación de las ciudades castellanas en comunidades políticas de perfil más próximo al de sus coetáneas de otros ámbitos europeos. Pero los obstáculos que impedían alcanzar este objetivo eran muchos e importantes, puesto que la preeminencia social y política alcanzada por la nobleza en las principales ciudades castellanas era ya a las alturas de principios del siglo XVI demasiado grande, y estaba firmemente consolidada. Y por ello el intento de suprimir las barreras estamentales en el seno de las estructuras políticas urbanas tropezó desde el primer momento con fuertes resistencias, porque incluso en las ciudades en que se produjo un triunfo más rotundo de la causa rebelde, los caballeros comuneros no aceptaron de muy buen grado que en las asambleas su opinión contase lo mismo que la de los más humildes representantes de las clases populares. Y de ahí que pronto surgiesen tensiones que, sin duda, contribuyeron decisivamente a debilitar a las Comunidades locales, y por derivación al movimiento comunero en su conjunto.

La Comunidad tenía en cada ciudad como célula básica la parroquia, o la cuadrilla en aquellos lugares en que ésta había sustituido a la primera como marco de agrupación de la población pechera, como era el caso, por ejemplo, de Soria. De manera que el desarrollo de dicha institución tuvo como presupuesto la revitalización de las asambleas de barrio, que durante mucho tiempo habían estado relegadas al desempeño de tareas irrelevantes desde el punto de vista político, relacionadas prioritariamente con la recaudación de impuestos, haciendo excepción de algunas ciudades de segundo rango en las que habían alcanzado escaso desarrollo los sistemas oligárquicos de gobierno, como eran, por ejemplo, las riojanas, donde también el papel político reconocido a estas asambleas de barrio seguía siendo notable a fines del siglo XV y principios del $\mathrm{XVI}^{67}$.

66 Sobre esta cuestión Vid. Diago Hernando, Máximo: «Las ciudades en Castilla y en el imperio alemán...»

67 Así en Logroño las collaciones y barrios habían tenido un papel fundamental en el proceso de elección de los oficiales hasta la modificación del modelo electoral en 1488. Y en Santo Domingo de la Calzada el regimiento tenía la obligación de informar a las cuadrillas de los temas que se trataban en concejo, pidiéndoles su opinión en determinados asuntos, y, en caso de elecciones disputadas, la responsabilidad de la elección de los oficiales pasaba a las cuadrillas. Vid. GOICOLEA JULIÁN, Francisco Javier: «Concejos urbanos...» pp. 241-5. 
En concreto en los años 1520 y 1521 las asambleas de parroquias o cuadrillas vieron sensiblemente reforzado su papel político en las grandes ciudades castellanas porque a ellas correspondió elegir a los diputados, que fueron oficiales con amplias atribuciones tanto en el ámbito político como en el militar, al estar encargados de administrar las armas para distribuirlas entre los vecinos en caso de peligro. Pero, además, estos diputados estaban obligados a someter a la consideración de las asambleas de cuadrilla muchas cuestiones de relevancia política local antes de que los órganos superiores de gobierno de la ciudad tomasen algún tipo de decisión en torno a ellas, por lo cual la influencia política de dichas asambleas quedaba considerablemente reforzada.

\section{CONCLUSIONES}

Aunque la historiografía ha solido prestar atención preferente a la faceta del movimiento comunero como rebelión de las ciudades contra la monarquía, no hay que olvidar que con ocasión del mismo tuvo lugar una fuerte movilización de los sectores sociopolíticos excluidos de la participación en el ejercicio del poder en las propias ciudades, que se marcó como principal objetivo la consecución de una reforma radical de los órganos de gobierno urbano, que acabase con el control ejercido sobre los mismos por las oligarquías nobles. Y, en efecto, estos sectores consiguieron imponer las reformas por ellos propiciadas en muchos e importantes núcleos urbanos, pero sus logros fueron en gran medida favorecidos por el clima de extrema inestabilidad que durante el año 1520 reinó en toda Castilla, y sobre todo en las ciudades de la meseta. Por lo cual, una vez que las tropas realistas consiguieron aplastar la rebelión en los campos de Villalar a fines de abril de 1521 , todos estos logros se vieron rápidamente anulados, ya que las oligarquías pasaron a quedar restablecidas en su posición dominante en todas y cada una de las principales ciudades castellanas, después, por supuesto, de haberse llevado a cabo algunas tareas de depuración mediante la destitución de aquellos regidores que más se habían comprometido en apoyar la rebelión, y su sustitución por otros individuos considerados más fieles.

En efecto, una de las principales consecuencias que para las ciudades castellanas tuvo la derrota de las Comunidades fue el fortalecimiento de la posición de las oligarquías al frente de los órganos de gobierno urbano, que se consiguió a costa de silenciar políticamente a los sectores dirigentes de la elite del Común, que en muchos casos no pudieron recuperar su voz hasta la segunda mitad del siglo XVIII, cuando Carlos III introdujo la figura institucional de los síndicos personeros del Común. De hecho, después de 1521 ya no se volvió a reproducir en las ciudades castellanas el clima de enfrentamiento entre regidores y sectores dirigentes del Común que se había vivido en las primeras décadas del XVI, y estos últimos perdieron rápidamente protagonismo en la vida política, incluso en aquellas ciudades en que la institución del Común de pecheros 
ya se encontraba plenamente consolidada desde hacía tiempo, como ocurría, por ejemplo, en Soria.

La derrota comunera hizo tomar conciencia a la elite del Común en las principales ciudades castellanas de que no era viable el camino escogido en 1520 para efectuar el asalto al poder, y que por lo tanto debía recurrir a otras vías para alcanzar la promoción social y política ${ }^{68}$. Y esta evolución sin duda contribuyó a dificultar el proceso de desarrollo de la burguesía como clase social en Castilla, porque propició que el poder político en las ciudades continuase en manos de la nobleza, y relegó a los mercaderes y hombres de negocios en general a una posición sociopolítica de segunda fila. Por lo cual, como consecuencia, la meta principal de todos estos individuos, que eran los que más contribuían a dinamizar la actividad económica de las ciudades, fue la de integrarse en el estamento privilegiado noble a costa del abandono de los negocios, una vez alcanzado el nivel de riquezas suficiente.

De hecho la revolución de las Comunidades representó el más ambicioso intento habido en la historia de Castilla de transformación de las estructuras sociopolíticas de sus ciudades para adaptarlas al modelo entonces vigente en los más dinámicos y avanzados núcleos urbanos del resto de Europa. En concreto se trataba sobre todo de conceder mayor protagonismo en la gestión de los asuntos públicos a los grupos más dinámicos de la sociedad, y de acabar con la concepción existente de los oficios públicos como bienes patrimoniales, para pasar a considerarlos preferentemente como una forma de servicio a la comunidad. Después de abril de 1521 ocurrió, sin embargo, todo lo contrario de lo que los sectores más radicales dentro del movimiento comunero habían propiciado. Pues, en lugar de atenuarse la concepción de los oficios de gobierno local como bienes patrimoniales, pasó por el contrario a quedar reforzada, al iniciarse en 1543 la política de venta de dichos oficios por parte de la monarquía.

Y, por si esto fuera poco, en el siglo XVIII, después de la Guerra de Sucesión, este modelo de gobierno local fue impuesto por la fuerza a las ciudades de los reinos de la Corona de Aragón. De manera que a comienzos del siglo XIX, cuando se iniciaron las revoluciones liberales, el conjunto de España distaba de encontrarse en las mejores condiciones para que éstas triunfasen sin dificultad, porque en los siglos precedentes no se había podido consolidar en sus núcleos urbanos una «burguesía» con conciencia política propia.

68 VAL VALDIVIESO, $M^{a}$. Isabel del: art. cit. pp. 249-50.

Hispania, LXIII/2, núm. 214 (2003) 623-656 